\title{
Analysis and Simulation of Wind Turbine Optimal Control Considering Wind Turbulence Characteristics
}

\author{
http://dx.doi.org/10.3991/ijoe.v11i5.4931 \\ $\mathrm{Gu}_{\mathrm{Bo}}{ }^{1,2}$, Liu Yongqian ${ }^{1}$, Hou Yuxiang ${ }^{2}$ and Kang Shun ${ }^{1}$ \\ ${ }^{1}$ North China Electric Power University, Beijing, China \\ ${ }^{2}$ North China University of Water Resources and Electric Power, Zhengzhou, China
}

\begin{abstract}
A maximum power point tracking (MPPT) algorithm of wind turbines considering wind turbulence characteristics is presented in this paper. The turbulence characteristics of natural wind are analyzed, and the natural wind speed model is established. A MPPT algorithm based on extremum-seeking control (ESC) is proposed, which considers the turbulence characteristics containing in wind speed. The goal of the MPPT algorithm is to keep the wind turbines running at the maximum wind energy utilization coefficient point stably. The algorithm is modeled and analyzed, and the simulation results show that the MPPT algorithm is correct and effective.
\end{abstract}

Index Terms-Wind turbine; Maximum power point tracking (MPPT); Extremum-seeking control (ESC); Wind turbulence characteristics.

\section{INTRODUCTION}

With the scarcity of fossil energy and the restrictions on carbon dioxide emission in worldwide, renewable energy has become the developing trend to mitigate the fossil energy issue. Wind power as a kind of renewable energy, with clean, large storage capacity and ease of development etc., is widely developed and utilized. In various energy shares, the proportion of wind energy is increasing. Therefore, improving the efficiency and stability of wind turbines has important significance for the development and utilization of wind energy.

At present, domestic and foreign researchers have being done a series of studies on the efficiency of wind energy capture, and have made some achievements. For small wind turbines, Narayana et al. [1] combined the fuzzy control technique and the adaptive filtering technique to realize the maximum power point tracking of wind turbines. The results show that the algorithm can improve the wind energy utilization efficiency by $20 \%$. RBF neural network and particle swarm algorithm were combined to realize the MPPT of small wind turbines, and the corresponding simulation model was established. The simulation results show that the algorithm can improve the utilization efficiency of small wind turbines to a certain extent [2]. Wang et al. [3] combined the disturbance signal and MPPT algorithm to improve the efficiency of MPPT algorithm. The calculation results show that this method can improve the efficiency of wind energy utilization for small wind turbines. The wind speed sensors installed on wind turbines can not accurately measure the wind speed at wind turbine locations because of the influence of wind rotor rotating airflow, which leads to that the MPPT algorithm relied on the measured wind speed can not accurately calculate the maximum power point of wind turbines. Therefore, Chen et al. [4-6] proposed the MPPT algorithm based on no-speed sensor vector control strategy, which uses the model reference adaptive system to accurately predict the rotation speed of wind rotor and then uses BP neural network to achieve the wind turbine maximum power point. Hill-climbing algorithm has the advantage of simplicity and practicality etc. However, this algorithm is prone to oscillate near the extreme points, which influences the stability of wind turbine operations. Thus, Hui et al. [7-9] combined hill-climbing algorithm and fuzzy logic control to solve the problem of the hill-climbing oscillations near the extreme points, and the efficiency of hillclimbing algorithm is improved. Esmaili et al. [10-11] did some researches about the operation principle of directdriven wind turbines, and proposed a corresponding MPPT control algorithm. Abdullah et al. [12] classified and summarized the current MPPT algorithms, which laid the foundation for the wind turbine MPPT technology researches.

Based on the existing maximum power tracking technology, a maximum power point tracking (MPPT) algorithm of wind turbines considering wind turbulence characteristics is presented in this paper. Firstly, the turbulence characteristics of natural wind are analyzed, and the natural wind speed model is established. Secondly, the principle that variable speed wind turbines convert wind energy into mechanical energy is analyzed, and the quantitative relationship between wind energy utilization coefficient and tip speed ratio is established. Finally, a MPPT algorithm of wind turbines considering wind turbulence characteristics is proposed, the goal of the MPPT algorithm is to keep the wind turbines running at the maximum wind energy utilization coefficient point stably. The algorithm is modeled and analyzed.

\section{NATURAL WIND SPEED MODEL}

The natural wind speed is random, which can be described by Van der Hoven wind speed spectrum model, as shown in Fig. 1.

Fig. 1 shows that the Van der Hoven wind speed spectrum model is composed of the mid-long term wind speed 
and the short-time wind speed (the dotted line part in Fig. 1 , the wind speed spectrum curve from the beginning of $10 \mathrm{~min}$ to the right). Short-time wind speed is the main factor that influences the dynamic characteristics and wind energy capture efficiency of wind turbines. Therefore, the wind speed model established in this paper is the shorttime wind speed model.

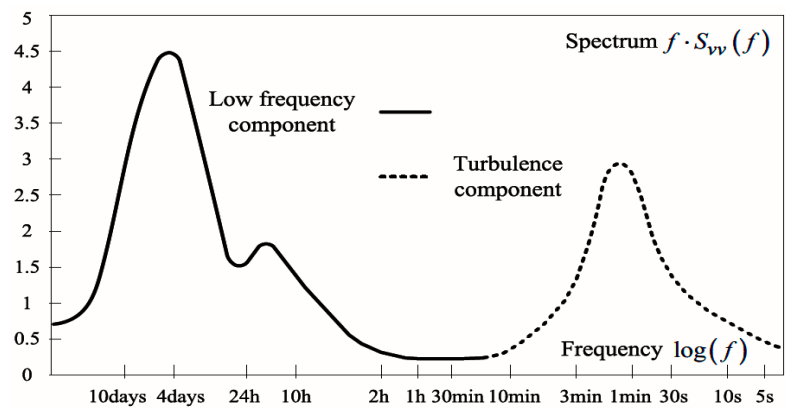

Figure 1. Van der Hoven spectral model of wind speed

The short-time wind speed of natural wind speed can be composed of average wind speed (the average wind speed between $10 \mathrm{~min}$ and $1 \mathrm{~h}$ ) and turbulence. The turbulence obeys Gauss normal distribution and the average value of Gauss normal distribution is zero. The standard deviation of Gauss normal distribution depends on the size of average wind speed. The short-time wind speed calculation equation is shown in (1).

$$
v(t)=v_{s}(t)+v_{t}(t)
$$

Where, $v_{s}(t)$ represents the average wind speed, typically taking $1 \mathrm{~h}$ average wind speed in the calculation; $v_{t}(t)$ represents turbulence. The value of $v_{s}(t)$ affects the turbulence magnitude.

The value of $v_{t}(t)$ can be obtained by multiplying the white noise with unit variance and the shaping filter. The power spectral density $S_{n}(w)$ of $v_{t}(t)$ can be calculated by equation (2).

$$
S_{v_{t}}(w)=\left|H_{t}(j w)\right|^{2} \cdot S_{n}(w)
$$

Where, $S_{n}(w)$ is the power spectral density of the white noise and its value is constant; $H_{t}(j w)$ is the transfer function of the shaping filter. Von Karman has put forward the transfer function expression of shaping filter, which is shown in equation (3).

$$
H_{t}(j w)=\frac{K_{F}}{\left(1+j w T_{F}\right)^{5 / 6}}
$$

Where, the time constant $T_{F}$ is $T_{F}=L / v_{s}(t)$. The value of $L$ can be selected according to the Denmark standard. According to the Danish standard, the expression of $L$ can be shown as equation (4).

$$
L=\left\{\begin{array}{lll}
150 m, & \text { when } & z \geq 30 m \\
5 z m, & \text { when } & \mathrm{z}<30 \mathrm{~m}
\end{array}\right.
$$

$K_{F}$ is the gain of the transfer function, and its formula is given as equation (5).

$$
K_{F}=\sqrt{\frac{2 \pi}{B(1 / 2,1 / 3)} \frac{T_{F}}{T_{S}}}
$$

Where, $T_{s}$ is the sampling time of white noise, and it can be configured. $B(x, y)$ is beta function.

The Von Carman filter in equation (3) is the non integer order filter, and the calculation process of the non integer order filter is difficult. Therefore, we use the improved Von Carman filter in this paper. The improved Von Karman filter has the integer order transfer function. The efficiency of the improved von Karman filter is same with the non integer order filter, but the calculation process becomes simple. The improved filter transfer function expression formula is shown as equation (6).

$$
H_{t}(j w)=K_{F} \frac{j w m_{1} T_{F}+1}{\left(1+j w T_{F}\right)\left(j w m_{2} T_{F}+1\right)}
$$

where, $m_{1}=0.4, m_{2}=0.25$.

Based on the above knowledge, the calculation process of turbulence can be shown in Fig. 2.

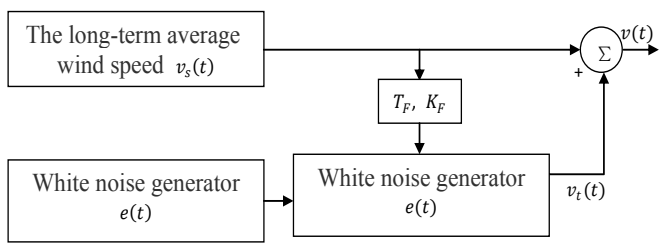

Figure 2. Calculation process of turbulence

According to Fig. 2, the calculation model of turbulence is established. Fig. 3 is 10 s wind speed distribution generated by the turbulence model. We can see from the figure that the size of turbulence fluctuation amplitude is related to the average wind speed $v_{s}(t)$. When $v_{s}(t)$ is $7 \mathrm{~m} / \mathrm{s}$, the fluctuation amplitude of turbulence is small; when $v_{s}(t)$ is $14 \mathrm{~m} / \mathrm{s}$, the fluctuation amplitude of turbulence is large. The conclusions are consistent with theoretical knowledge.

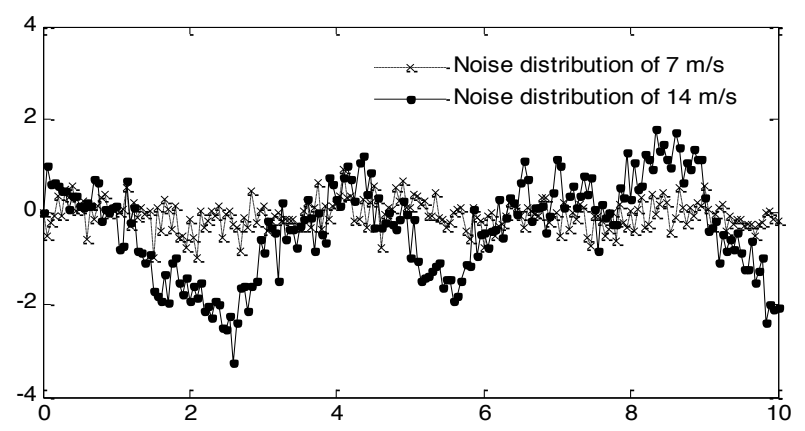

Figure 3. Simulation of turbulence

Fig. 4 shows the statistical characteristics of turbulence. We can obtain from Fig. 4 that the turbulence obeys Gauss normal distribution. The value of the standard deviation $\sigma$ depends on the average wind speed $v_{s}(t)$. When the average wind speed $v_{s}(t)$ is $14 \mathrm{~m} / \mathrm{s}$, standard deviation is bigger than that of the average wind speed $7 \mathrm{~m} / \mathrm{s}$. The above simulation results prove the correctness of the established turbulence model. 


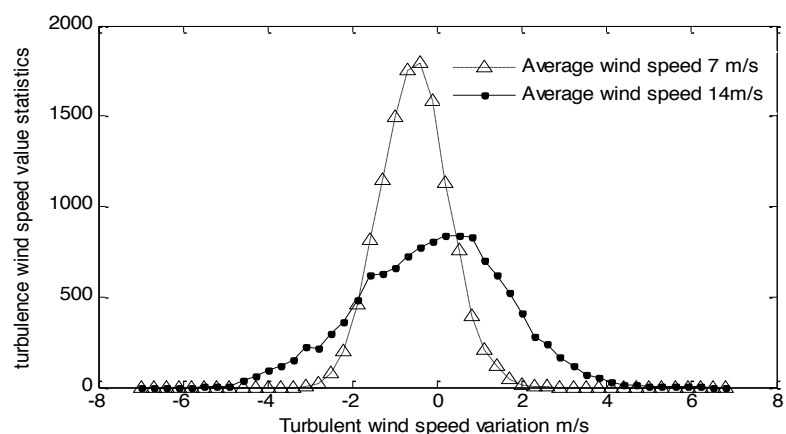

Figure 4. Statistical characteristics of turbulence

\section{WIND TURBINE AERODYNAMICS}

Wind turbines are the equipment that can convert wind energy into mechanical energy. The size that wind turbines convert wind energy into mechanical energy is related to wind speed 3-th power, and the relationship can be expressed as equation (7).

$$
P_{W T}=\frac{1}{2} \rho \pi R^{2} v^{3} C_{p}(\beta, \lambda)
$$

In equation (7), $P_{V T}$ is the wind turbine mechanical power; $\rho$ is the air density; $R$ is the rotor radius; $v$ is the wind speed; $\beta$ is the pitch angle; $\lambda$ is the tip speed ratio; $C_{p}$ is the wind energy utilization coefficient of wind turbines. The relationships among $C_{p}, \beta$ and $\lambda$ are expressed as equations (8).

$$
\left\{\begin{aligned}
C_{p}(\beta, \lambda) & =0.22\left(\frac{116}{\lambda_{i}}-0.4 \beta-5\right) e^{-\frac{22.5}{\lambda_{i}}} \\
\frac{1}{\lambda_{i}} & =\frac{1}{\lambda+0.08 \beta}-\frac{0.035}{\beta^{3}+1}
\end{aligned}\right.
$$

Fig. 5 illustrates the coupling relationship among $C_{p}$, $\beta$ and $\lambda$.

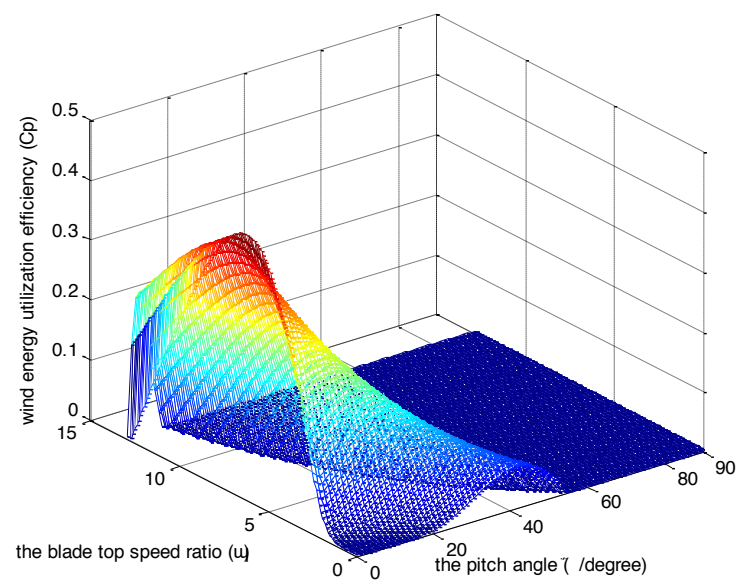

Figure 5. Relationship among $C_{p}, \beta$ and $\lambda$

This paper focuses on the MPPT technology of variable speed wind turbines. In order to facilitate the analysis of the main issues, the variable speed wind turbines are assumed to operate at below the rated wind speed during the study. Under this condition, the pitch angle is zero degree, and the size of $C_{p}$ is only related to $\lambda$. The rela- tionship between $C_{p}$ and $\lambda$ can be shown in Fig. 6. It can be seen from Fig. 6 that the wind energy utilization coefficient $C_{p}$ is a monopole function of the tip speed ratio $\lambda$. Thus, it is possible to achieve the maximum wind energy utilization coefficient $C_{p \max }$ and the optimum tip speed ratio $\lambda_{\text {opt }}$.

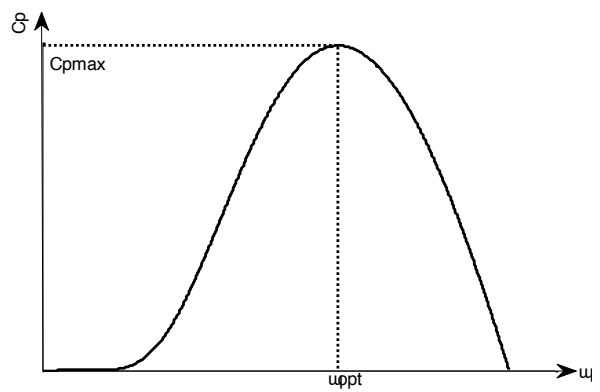

Figure 6. Relationship between $C_{p}$ and $\lambda$

Fig. 7 depicts the coupling relationships among wind speed, rotational speed and output power. It can be seen from Fig. 7 that the output power of wind turbines changes with the rotational speed change under a certain wind speed. Therefore, we can obtain the maximum power of wind turbines under a certain wind speed by adjusting the rotational speed.

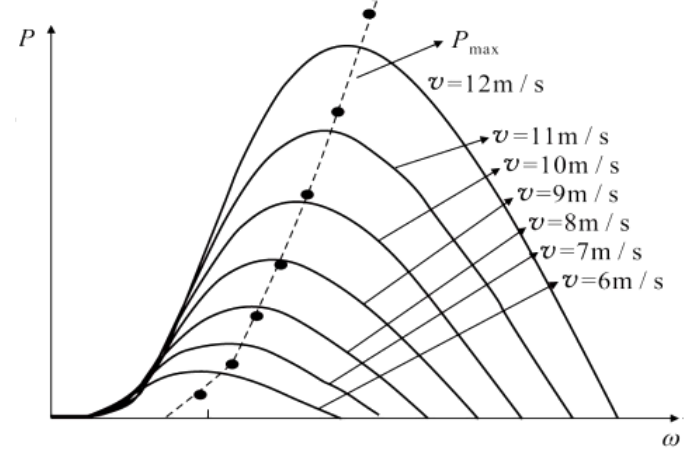

Figure 7. Relationships among wind speed, rotational speed and output power

\section{EXTREMUM-SEEKING CONTROL}

\section{A. Principle of Extremum-seeking Control}

It can be known from the relationship between $C_{p}$ and $\lambda$ in Fig. 6 that $C_{p}$ has a unique maximum wind energy utilization coefficient $C_{p \max }$ in the change process of tip speed ratio $\lambda$. Therefore, we could use extremum-seeking control algorithm to search the optimal tip speed ratio value $\lambda_{\text {opt }}$ in which the wind energy utilization coefficient $C_{p}$ can obtain maximum $C_{p \max }$.

Fig. 8 is a schematic diagram of extremumseeking control. In Fig. 8, $s /(s+h)$ is high-pass filter; $\mathrm{k} / \mathrm{s}$ is integrator; $\xi$ is the output signal of wind energy utilization coefficient $C_{p}$ after high-pass filter; $\xi$ is the output signal of $\xi$ after superimposed sinusoidal; $a$ is the amplitude of excitation signal; $\hat{\lambda}$ is the estimated value of the optimal tip speed ratio $\lambda_{\text {opt }}$ [13]. 


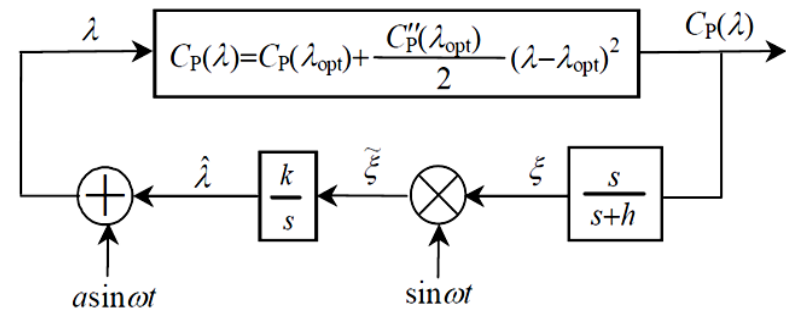

Figure 8. Schematic diagram of extremum-seeking control

The wind energy utilization coefficient function $C_{p}(\lambda)$ is carried out by the 2 order Taylor series expansion at the optimal tip speed ratio $\lambda_{\text {opt }}$. Due to $C_{p}\left(\lambda_{\text {opt }}\right)=0$, so equation (9) can be achieved.

$$
C_{p}(\lambda)=C_{p}\left(\lambda_{\text {opt }}\right)+\frac{C_{p}^{\prime \prime}\left(\lambda_{\text {opt }}\right)}{2} \times\left(\lambda-\lambda_{\text {opt }}\right)^{2}
$$

We can define $\Re \in \lambda_{\text {opt }} \$$ as search error, and equation (10) can be got by taking $\$$ into equation (9).

$$
\begin{aligned}
\mathrm{C}_{p}(\lambda)= & \mathrm{C}_{p}\left(\lambda_{\mathrm{opt}}\right)+\frac{\mathrm{a}^{2} \mathrm{C}_{p}^{\prime \prime}\left(\lambda_{\mathrm{opt}}\right)}{4}+\frac{\mathrm{C}_{p}^{\prime \prime}\left(\lambda_{\mathrm{opt}}\right)}{2} \lambda^{\%_{-}} \\
& \mathrm{a}^{2} \mathrm{C}_{p}^{\prime \prime}\left(\lambda_{\mathrm{opt}}\right) \sin (w t)+ \\
& \frac{\mathrm{a}^{2} \mathrm{C}_{p}^{\prime \prime}\left(\lambda_{\mathrm{opt}}\right)}{4} \cos (2 w t)
\end{aligned}
$$

The output value of $C_{p}(\lambda)$ is filtered by the high-pass filter in Fig. 8. Equation (11) can be achieved by demodulating the filter output value using signal wave $\sin (w t)$.

$$
\begin{aligned}
\xi \approx- & \frac{a C_{p}^{\prime \prime}\left(\lambda_{\mathrm{opt}}\right)}{2} \mathrm{R} / q \frac{a C_{p}^{\prime \prime}\left(\lambda_{\mathrm{opt}}\right)}{2} \mathrm{R} / \cos (2 w t)+ \\
& \frac{a^{2} C_{p}^{\prime \prime}\left(\lambda_{\mathrm{opt}}\right)}{8} \times(\sin (w t)-\sin (3 w t))+ \\
& \frac{C_{p}^{\prime \prime}\left(\lambda_{\mathrm{opt}}\right)}{2} \mathrm{R} / \mathrm{sin}(w t)
\end{aligned}
$$

Since $\xi=\sin (w t)+\xi$, we can do integral computation on $\xi$. The integral result is shown in equation (12).

$$
\begin{aligned}
& \$ \approx-\frac{k}{s}\left[-\frac{a C_{p}^{\prime \prime}\left(\lambda_{\text {opt }}\right)}{2} \mathbb{R} q \sin (w t)+\frac{a C_{p}^{\prime \prime}\left(\lambda_{\text {opt }}\right)}{2} \mathbb{R} \cos (2 w t)+\right. \\
& \frac{a^{2} C_{p}^{\prime \prime}\left(\lambda_{\text {opt }}\right)}{8} \times(\sin (w t)-\sin (3 w t))+ \\
& \left.\frac{C_{p}^{\prime \prime}\left(\lambda_{\text {opt }}\right)}{2} \% \%_{\sin }(w t)\right]
\end{aligned}
$$

In equation (12), the last 4 terms on the right side are high-frequency components. The four terms attenuate greatly after integral computation and can be neglected. Because the value of $\lambda_{\text {opt }}$ is constant, thus the equation that $\dot{q}^{\dot{0}}=-\$$ can be achieved. Therefore, equation (12) can be simplified as equation (13).

$$
\mathrm{Q} \% \frac{k a \mathrm{C}_{p}^{\prime \prime}\left(\lambda_{\text {opt }}\right)}{2} \mathrm{k}
$$

Because $C_{p}(\lambda)$ has a unique extreme value, it can be known from the mathematical knowledge that $C_{\ddot{p}}\left(\lambda_{\text {opt }}\right)<0$. Assumed $k>0$ and $a>0$, then $\dot{\phi}<0$. So, equation (9) can converge to $\% \underline{0}$ stably. At this time $\lambda_{\text {opt }}=\$$, the wind energy utilization coefficient function $C_{p}(\lambda)$ searches the maximum value $C_{p \max }$. Accordingly, the wind turbine MPPT algorithm is completed.

\section{B. Wind Turbine Extremum-seeking Process}

The phase relationship between the wind energy utilization coefficient $C_{p}(\lambda)$ and the tip speed ratio $\lambda$ is shown in Fig. 9. In the processes of searching the maximum value of $C_{P}(\lambda)$, letting the tip speed ratio $\lambda$ superimpose a sinusoidal excitation signal that the frequency is $\omega$ and the amplitude is $a$. Accordingly, the output value of $C_{p}(\lambda)$ also has a sinusoidal variation. When the operation point is located on the left side of the maximum value point $C_{p \max }$, the wind energy utilization coefficient function $C_{p}(\lambda)$ will increase as the tip speed ratio $\lambda$ increases, the phase $\theta$ of $C_{p}(\lambda)$ and $\lambda$ is less than $\pi / 2$. When the operation point is located on the right side of the maximum value point $C_{p \max }$, the wind energy utilization coefficient function $C_{p}(\lambda)$ will decrease as the tip speed ratio $\lambda$ increases, the phase $\theta$ of $C_{p}(\lambda)$ and $\lambda$ is more than $\pi / 2$. When the operation point is located at the maximum value point $C_{p \max }$, the phase $\theta$ of $C_{p}(\lambda)$ and $\lambda$ is equal to $\pi / 2$. The operational status of wind turbines and the direction of tip speed ratio $\lambda$ can be determined by analyzing the size of the phase $\theta$.

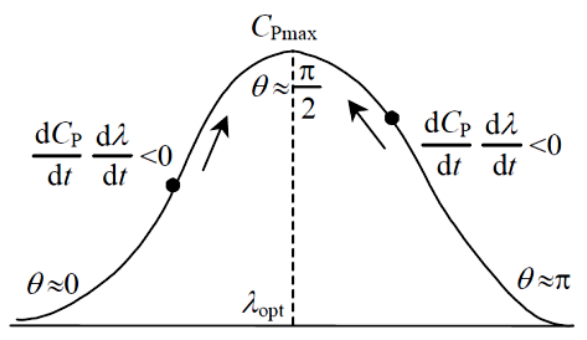

Figure 9. Phase relationship between $C_{p}(\lambda)$ and $\lambda$

\section{EXTREMUM-SEEKING CONTROL CONSIDERING TURBULENCE CHARACTERISTICS}

As a power source for wind power generation system, wind speed has high frequency turbulence. The high frequency turbulence can result in the tip speed ratio of wind turbines change. In the process of maximum power point tracking by using extremum-seeking control algorithm, because of the interference of the high frequency turbulence, the output superposition signal has high frequency random components. It is difficult to separate the standard sinusoidal signal from the output superposition signal. Therefore, a new method is proposed to realize the extremum-seeking control algorithm in this paper, and the turbulence is used to instead of sinusoidal signal as the excitation signals in the method.

According to the measurement data, we can obtain generator power $P_{t}$, generator rotational speed $\omega_{s}$, wind speed $v$, transmission efficiency $\eta$ and transmission ratio $K_{G}$. The tip speed ratio $\lambda(t)$ and the wind energy utilization coefficient $\mathrm{C}_{p}(t)$ can be calculated according these measurement data. The calculation process is shown in equation (14).

$$
\left\{\begin{array}{l}
\lambda(t)=\frac{R \omega_{G}(t)}{K_{g} v(t)} \\
\mathrm{C}_{P}(t)=P_{G} /\left[0.5 \eta \pi R^{2} v^{3}(t)\right]
\end{array}\right.
$$


As the tip speed ratio $\lambda(t)$ and the wind energy utilization coefficient $\mathrm{C}_{p}(t)$ have random characteristics. In order to determine the phase relationship between $\lambda(t)$ and $\mathrm{C}_{p}(t)$, the tip speed ratio $\lambda(t)$ and the wind energy utilization coefficient $\mathrm{C}_{p}(t)$ are made Fourier transformation and decomposed into multiple sinusoidal harmonics. The time length of the Fourier transform is $2^{n} T_{s}, T_{s}$ is the sampling time.

$C_{p}(t)$ is the monopole function of $\lambda(t)$. Therefore, each harmonic component of $\lambda(t)$ can generate the corresponding component in $\mathrm{C}_{p}(t)$. Then, the phase relation of each harmonic component of $\mathrm{C}_{p}(t)$ and $\lambda(t)$ can be compared, and the phase relations of all the harmonic components of $\mathrm{C}_{p}(t)$ and $\lambda(t)$ are averaged and the average is $\theta(t)$. $\theta(t)$ can be seen as the phase relation of $\mathrm{C}_{p}(t)$ and $\lambda(t)$. The change direction of tip speed ratio could be determined by the size of $\theta(t)$. According to the principle of extremumseeking control algorithm shown in Fig. 9, the change of the tip speed ratio is made integral operation. The tip speed ratio reference value $\lambda^{*}$ in next time can be obtained. The calculation process of $\lambda^{*}$ is shown in equations (15) and (16).

$$
\begin{gathered}
\left\{\begin{array}{l}
\operatorname{sgn}\left[\frac{\pi}{2}-\theta(t)\right]=1 \\
\lambda^{*}(t+1)=\lambda(t)+\int k d t
\end{array} \quad \text { when } \theta(t)<\frac{\pi}{2}\right. \\
\left\{\begin{array}{l}
\operatorname{sgn}\left[\frac{\pi}{2}-\theta(t)\right]=-1 \\
\lambda^{*}(t+1)=\lambda(t)-\int k d t
\end{array} \quad \text { when } \theta(t)>\frac{\pi}{2}\right.
\end{gathered}
$$

Where, $k$ is the integral constant, the value size of $k$ determines the search speed and accuracy. When $\theta(t)=\pi / 2$, $C_{p}(\lambda)$ reaches the maximum value point $C_{p \max }$.

\section{EXAMPLE ANALYSES}

The simulation model of variable speed wind turbines is established according to the above mathematical model, and the maximum power tracking algorithm of variable speed wind turbines considering the wind turbulence characteristics is calculated and analyzed. The model parameters of variable speed wind turbines are shown in Tab. 1.

TABLE I. MODEL PARAMETERS OF WIND TURBINES

\begin{tabular}{c|l|l}
\hline Rotor & \multicolumn{1}{|c}{ Drive chain } & \multicolumn{1}{c}{ DFIG } \\
\hline & & $p=2, R_{\mathrm{s}}=1.265 \Omega$, \\
& & $R_{\mathrm{r}}=1.265 \mathrm{~m} \Omega$ \\
& & $L_{\mathrm{m}}=0.1397 \mathrm{H}$, \\
Blade length: & Multiplier ratio: $i=6.25$ & $L_{\mathrm{s}}=0.1452 \mathrm{H}$ \\
$R=2.5 \mathrm{~m}$ & Lss inertia: $J_{\mathrm{h}}=0.5 .42 \mathrm{kgm}^{2}$ & $L_{\mathrm{r}}=0.1452 \mathrm{H}$, \\
& Efficiency: $\eta=0.95$ & $\omega_{\mathrm{s}}=100 \pi \mathrm{rad} / \mathrm{s}$ \\
& & $\Gamma_{\mathrm{Gmax}}=40 \mathrm{Nm}$, \\
& & $V_{\mathrm{s}}=220 \mathrm{~V}$ \\
& & \\
\hline
\end{tabular}

The simulation system structure of variable speed wind turbines is shown in Fig. 10. Wind turbine, anemometer, gearbox, generator, control system and power system are contained in Fig. 10. The anemometer is used to measure wind speed of wind turbines, and provide data support for constructing the MPPT algorithm considering wind turbulence characteristics.

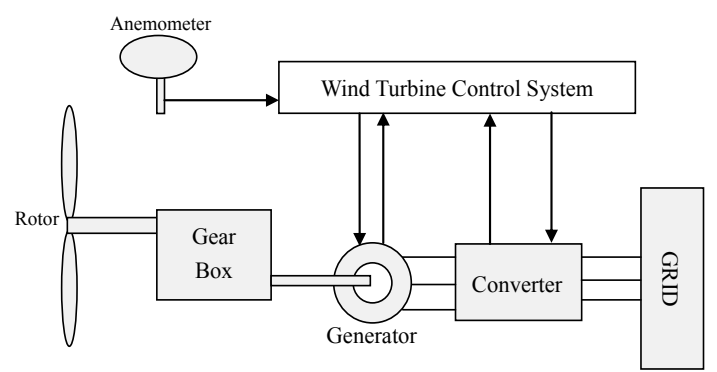

Figure 10. wind turbine system structure

Fig. 11 shows the wind speed data of the simulation model, and the simulation time is 300 seconds. The wind speed data is calculated according to Van der Hoven wind speed spectrum model. The wind speed data in the figure have random characteristics significantly, and it accords with the law of natural wind speed.

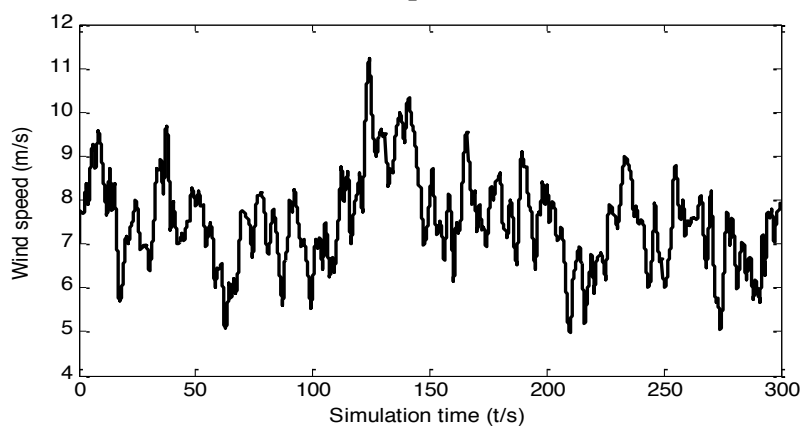

Figure 11. Wind speed data

Fig. 12 is the tip speed ratio of variable speed wind turbines. From the figure we can clearly see that with the change of wind speed, the MPPT algorithm considering wind turbulence characteristics can make the wind turbine running smoothly in the vicinity of the optimal tip speed ratio. The fluctuation range of tip speed ratio is small, so that the wind turbine can capture more wind energy. In the same time, the wind turbine runs stability.

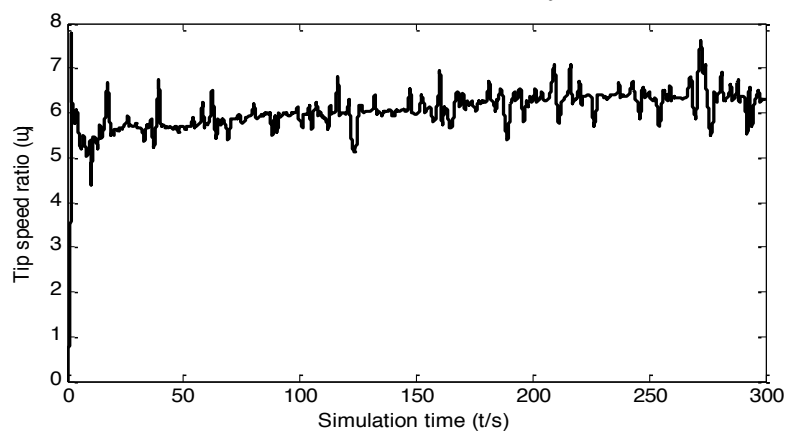

Figure 12. Tip speed ratio

Fig. 13 shows the wind energy utilization coefficient of wind turbines. From the figure we can clearly see that the MPPT algorithm considering wind turbulence characteristics can make the wind energy utilization coefficient of wind turbines running smoothly above 0.4. The MPPT algorithm considering wind turbulence characteristics not only improves the utilization efficiency of wind energy, but also ensures the stability of the wind turbine operation. 


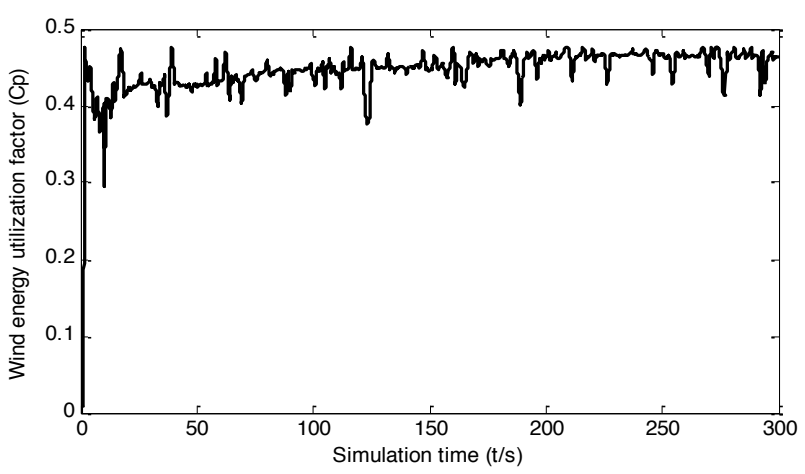

Figure 13. Wind energy utilization coefficient

Fig. 14 shows that the phase $\theta(t)$ of $C_{p}(\lambda)$ and $\lambda$ changes with the running time. It can be seen from the figure that the phase $\theta(t)$ changes with the change of wind speed. However, the value of the phase $\theta(t)$ is fluctuating mainly near $\pi / 2$. This means that the wind turbine operates at the vicinity of the maximum wind energy utilization coefficient. Accordingly, the maximum power point tracking considering wind turbulence characteristics is proved to be effective.

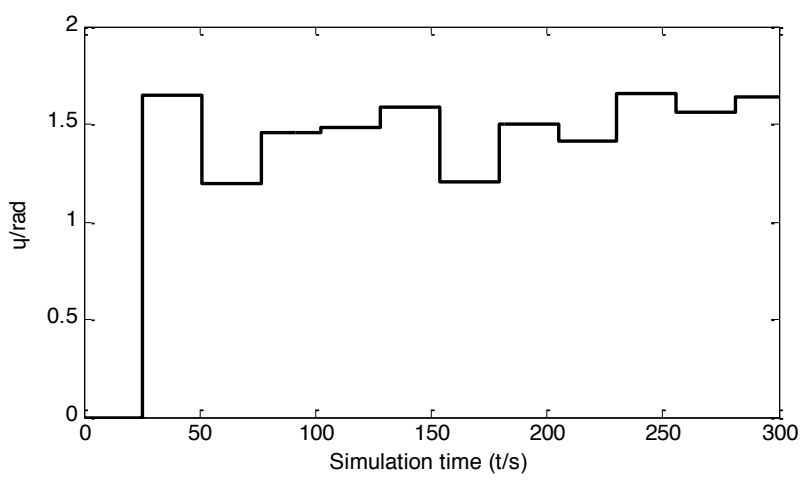

Figure 14. Change chart of the phase difference $\theta(t)$

From the above analysis, the MPPT algorithm considering wind turbulence characteristics can make the variable speed wind turbines running in the vicinity of the maximum wind energy utilization coefficient. It realizes the optimization control of wind turbines, and keeps the wind turbines to run stably.

\section{CONCLUSIONS}

Based on the existing maximum power tracking technology, a MPPT algorithm considering wind turbulence characteristics is presented in this paper. Firstly, the turbulence characteristics of natural wind are analyzed, and the natural wind speed model is established. Secondly, the principle that the variable speed wind turbines convert wind energy into mechanical energy is analyzed, and the quantitative relationship between the wind energy utilization coefficient and the tip speed ratio is established. Finally, a MPPT algorithm considering wind turbulence characteristics is presented, the goal of the MPPT algorithm is to keep the wind turbines running at the maximum wind energy utilization coefficient point stably.

The algorithm is modeled and analyzed, and the simulation results show that the MPPT algorithm considering wind turbulence characteristics can make the wind energy utilization coefficient of wind turbines running smoothly above 0.4. It improves the utilization efficiency of wind energy, and reduces the fluctuation of wind turbines.

\section{ACKNOWLEDGMENT}

This study is supported by 863 major projects of the Ministry of Science and Technology of China (SQ2010AA0523193001). Moreover, the authors wish to thank these people who have given a lot of help for the study, but their names are not listed in the paper.

\section{REFERENCES}

[1] M. Narayana, G.A. Putrus, M. Jovanovic, P.S. Leung, S. McDonald, "Generic maximum power point tracking controller for smallscale wind turbines", Renewable Energy, V. 44, pp. 72-79, August 2012. http://dx.doi.org/10.1016/j.renene.2011.12.015

[2] L. C. Yao, C. P. Hung, S. Y. Xing, "Maximum power point tracking (MPPT) system of small wind power generator using RBFNN approach", Expert Systems with Applications, V. 38, pp. 1205812065, September 2011. http://dx.doi.org/10.1016/j.eswa. 2011.02.054

[3] S. T. Wang, Z. Y. Qi, T. Undeland, "State Space Averaging Modeling and Analysis of Disturbance Injection Method of MPPT for Small Wind Turbine Generating Systems", Power and Energy Engineering Conference, Wuhan, 27-31 March 2009. http://dx.doi.org/10.1109/appeec.2009.4918780

[4] C. H. Chen, C. M. Hong, F. S. Cheng, "Intelligent speed sensorless maximum power point tracking control for wind generation system", Electrical Power and Energy Systems, V. 42, pp. 399407, November 2012. http://dx.doi.org/10.1016/j.ijepes. 2012.04.019

[5] J. S. Thongam, P. Bouchard, H. Ezzaidi, M. Ouhrouche, "Wind speed sensorless maximum power point tracking control of variable speed wind energy conversion systems", Electric Machines and Drives Conference, Miami, 3-6 May 2009. http://dx.doi.org/10.1109/iemdc.2009.5075452

[6] S. M. R. Kazmi, H. Goto, H. J. Guo, O. Ichinokura, "A Novel Algorithm for Fast and Efficient Speed-Sensorless Maximum Power Point Tracking in Wind Energy Conversion Systems", IEEE Transactions on Industrial Electronics, V. 58, pp. 29-36, January 2011. http://dx.doi.org/10.1109/TIE.2010.2044732

[7] J. Hui, A. Bakhshai, "Adaptive Algorithm for Fast Maximum Power Point Tracking in Wind Energy Systems", 34th Annual Conference of IEEE, Orlando, 10-13 November 2008. http://dx.doi.org/10.1109/iecon.2008.4758284

[8] K. S. M. Raza, H. Goto, H. J. Guo, O. Ichinokura, "A Novel Algorithm for Fast and Efficient Maximum Power Point Tracking of Wind Energy Conversion Systems", Proceedings of the 2008 International Conference on Electrical Machines,Vilamoura, 6-9 September 2008. http://dx.doi.org/10.1109/ICELMACH.2008. $\underline{4800030}$

[9] [9] G. Joseph, J. C. Foreman, M. L. McIntyre, “A Variable Duty Cycle Maximum Power Point Tracking Algorithm for Wind Energy Conversion Systems", Power Electronics and Machines in Wind Applications (PEMWA), Denver, 16-18 July 2012.

[10] R. Esmaili, L. Xu, D. K. Nichols, "A New Control Method of Permanent Magnet Generator for Maximum Power Tracking in Wind Turbine Application", Power Engineering Society General Meeting , USA. 12-16 June 2005. http://dx.doi.org/10.1109/ pes.2005.1489319

[11] Y. Xia, K. H. Ahmed, B. W. Williams, "A New Maximum Power Point Tracking Technique for Permanent Magnet Synchronous Generator Based Wind Energy Conversion System", IEEE Transactions on Power Electronics, V. 26, pp. 3609-3620, December 2011. http://dx.doi.org/10.1109/TPEL.2011.2162251

[12] M. A. Abdullah, A. H. M. Yatim, C. W. Tan, R. Saidur, "A review of maximum power point tracking algorithms for wind energy systems", Renewable and Sustainable Energy Reviews, V. 16, pp. 3220-3227, June 2012. http://dx.doi.org/10.1016/j.rser. $\underline{2012.02 .016}$ 
[13] K. B. Ariyur, M. Krstić, Real-time optimization by extremum seeking control, New Jersey: Wiley-Interscience, Hoboken, 2003. http://dx.doi.org/10.1002/0471669784

\section{AUTHORS}

Gu Bo, received the Master degree in North China University of Water Resources and Electric Power in 2006. Currently, he is a lecturer at North China University of
Water Resources and Electric power, Henan 450011, china (e-mail:gb19820915@163.com).

Liu Yongqian, was with the Renewable Energy Department, North China Electric Power University, ChangPing, Beijing, 102206 China. He is professor of this university (e-mail: 295901407@qq.com ).

This study is supported by 863 major projects of the Ministry of Science and Technology of China (SQ2010AA0523193001). Submitted 05 August 2015. Published as resubmitted by the authors 30 August 2015 